International Journal of Engineering \& Technology, $7(4.6)(2018) 112-116$
International Journal of Engineering \& Technology
SPC
Website: www.sciencepubco.com/index.php/IJET
Research paper

\title{
Towards Cloud of Things from Internet of Things
}

\author{
D. Vaishnavi ${ }^{1 *}$, Shawon Rahman ${ }^{2}$, D. Ramalingam ${ }^{3}$ \\ ${ }^{1}$ Dept. of CSE, Vardhaman College of Engg., Hyderabad, Telangana, India \\ ${ }^{2}$ Dept. of CSE, University of Hawai 'i, Hilo, USA \\ ${ }^{3}$ Faculty of IT, Majan College, Muscat, Sultanate of Oman \\ *Corresponding author E-mail:vaishume11@gmail.com,
}

\begin{abstract}
The techniques Internet of things (IoT) and Cloud Computing (CC) are becoming a part of our day-to-day life; where IoT connects a billion numbers of devices to share the information by communicating each other and CC grants convenient, on-demand scalable network access in order to utilize the computing resources and it facilitates dynamic data integration from diverse sources. Both techniques are having their own pros and cons. So, a novel paradigm called cloud of things (CoT) is modeled by integrating the both CC and IoT, which enables a large number of applications to get advantages of IoT as well as CC. This paper delivers the basics of the technologies, motivations to model the cloud of things and its benefits. Also, it discusses the implementation challenges.
\end{abstract}

Keywords: Cloud computing; Internet of Things; cloud of things; security; challenges.

\section{Introduction}

Internet of Things (IoT) is a dynamic and wide-ranging network infrastructure of interconnected self-configuring nodes. It is fundamentally regarded as widely distributed, real world small things and it has limited storage and processing capacity to attain performance, security, reliability and privacy. In contrast, Cloud computing has almost boundless of storage and processing capacity, is an advanced technology and it has greater number of IoT problems at least partially elucidated [1], [2]. Accordingly, a new paradigm is innovated to heighten the both recent and future network development, is the integration of cloud and IoT, called Cloud of Things (CoT). This integrated technology carries the following characteristics:

On-market self-services: The services related to cloud always depend on the web and realizes the information deprived of any special benefits from society.

Wide range of network access: It provides diverse connectivity alternatives. The resources required for cloud can be collected via a wide range of network connected devices such as laptops, tablets and mobile phones.

Resource polling: It represents the way, how the information can be shared with the user at anywhere and anytime by means of the needed authorizations for gaining the access.

Elasticity: It describes about adding or removing the users, editing the software setup simply and quickly, networking and also delivers about the increasing storage space.

Measured service: It calculates the data usage like bandwidth, data storage and active user accounts in cloud space.

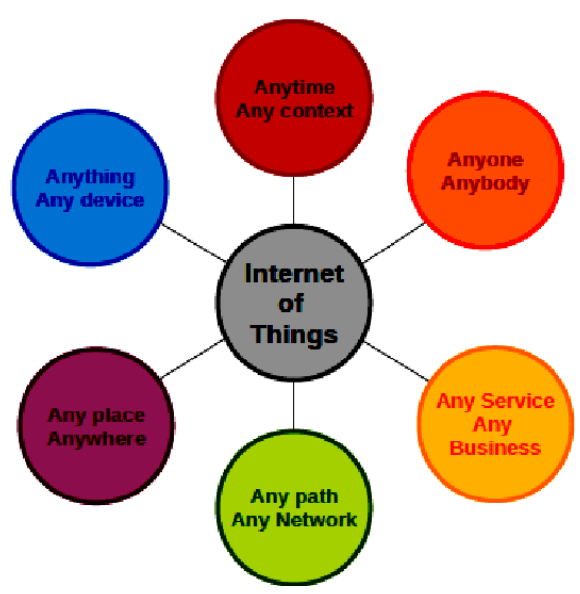

Fig. 1. Definition of IoT

\section{Basic concepts}

This section discusses basic concepts of Internet of Things and cloud computing along with its advantages and drawbacks, it delivers.

\subsection{Internet of Things}

IoT has been popularized since the last few years, and which refers to a world-wide network of uniquely addressable interconnected things/devices; identification of devices is based on the standard communication internet protocols [3], [4]. The key thought behind the IoT is, the people able to measure, understand, infer and even is able to modify the environmental things what are all ubiquitously presented around them as shown in Fig.1. 
IoT is operated by the advanced communication technologies and variety of devices, rather things incorporated in IoT are not only complex devices like mobile phones, instead it also includes dayto-day objects like clothing, furniture, landmarks, paper, monuments, work of art, etc [5], [6]. These things act as actuators or sensors, which are able to work together with each other to accomplish a goal.

The main feature of IoT is its influence on daily life of users [7]. It has incredible effects in home scenarios as well as work scenarios such as assisted living, e-health, and smart transportation etc. A few key aspects of IoT are described below:

RFID: Radio-Frequency Identification (RFID) system is main component in any IoT model, which incorporates one or more readers and several tags. It helps in automatic identification of anything they are attached to and allow objects to be assigned unique digital identities, to communicate with digital services. RFID tags don't require on-board power supply, but it consumes power from batteries [7], [8].

Sensor Networks (wireless): It contains a huge number of sensing nodes, and their communication takes place in multi-hop fashion. Special nodes called sinks are used to collect the results. Wireless sensor networks (WSN), provides various data that are being utilized in government and environmental services, defense and healthcare etc. It also may face many issues like security, reliability, privacy, storage capacity, bandwidth etc [7], [9].

Addressing: The evolution of internet led the people to interconnect unprecedentedly, but now the trend is to interconnect the object to make to the environment as smart [10]. In this regard, things or objects needs to be uniquely identified, this unique identification can be addressed by IPv4 and IPv6.

Middleware: Since the limited storage and processing capabilities, the participation of objects in the network is heterogeneous. So, the middleware plays a key role between the things and the application layer, in order to provide the functional abstraction. The middleware consists a set of object abstraction service management, service composition and application layers as shown in the Fig. 2 [5].

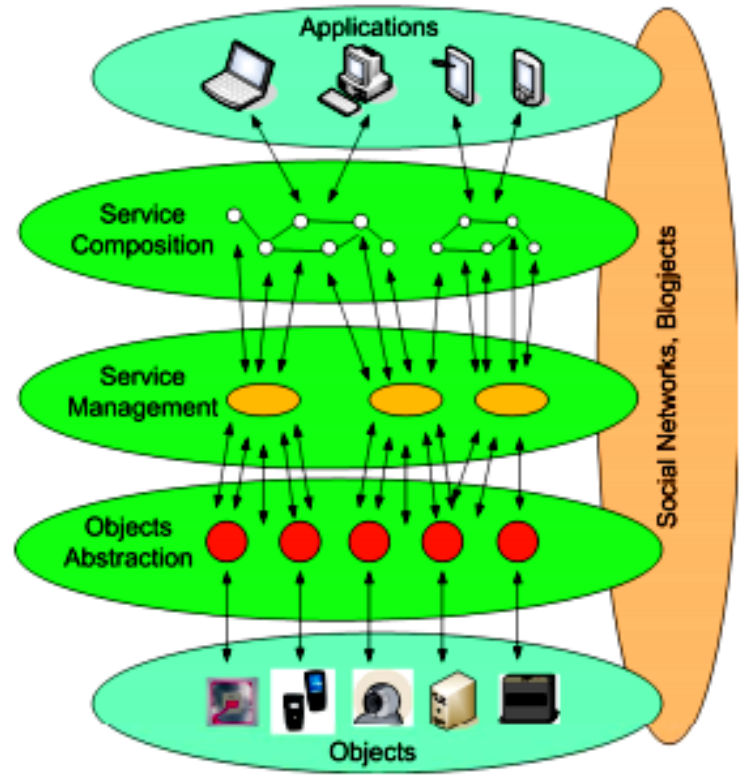

Fig. 2: Middleware architecture of IoT

\subsection{Cloud Computing}

Cloud computing is a disruptive technology with insightful implications to bring the various internet services. Large companies like google, amazon, facebook, etc. widely took this paradigm for delivering services via the internet, also gaining both technical and economical benefits. Even though some of issues have been found in each service models, those are associated to security, privacy and service-level agreements, which might be an alarming issues of potential users [11]. Also, the lack of standard APIs prevents the customers to simply fetch the code and data from a site in order to run in another. Fig. 3 précises the cloud service models and its benefits by means of layered architecture fashion.

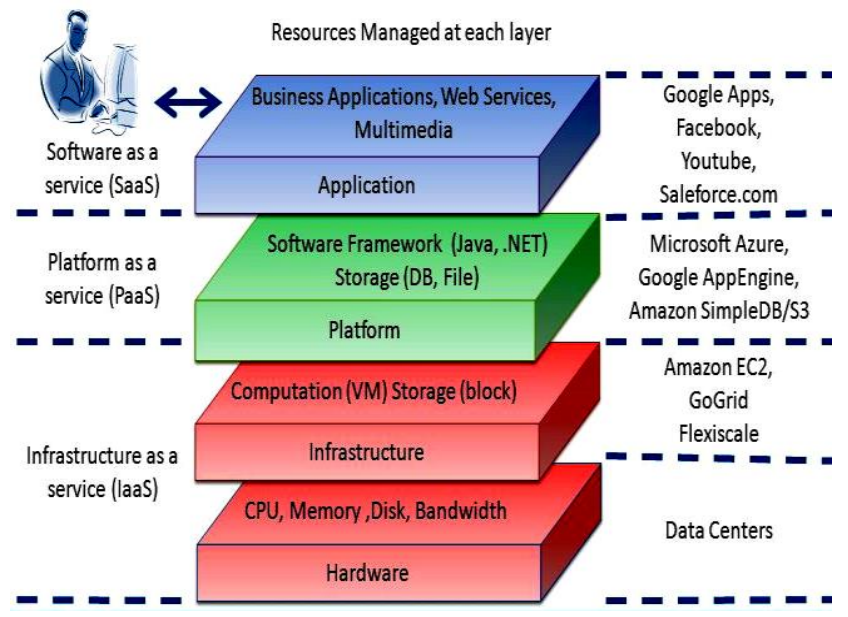

Fig. 3: Cloud computing: layered view

The architecture of cloud contains four layers; they are data centre (hardware), infrastructure, platform and application [12], [13]. Cloud services are divided as follows:

Software as a Service (Saas): It denotes the functioning of applications over the cloud.

Platform as a Service (PaaS): It denotes platform layer resources.

Infrastructure as a Service (IaaS): It refers the resources such as network, storage and processing. It permits the consumer to govern the storage, operating system and applications.

Types of Clouds: As stated in the literature, cloud can be various types. They are:

(i) Private: It is used typically owned, operated a managed by sing organization.

(ii) Public: It is provisioned to custom usage by the public.

(iii) Hybrid: It is a combination of more than one distinct cloud structure.

(iv) Virtual Private: It aims to addressing the issues related to public and private clouds. It permits the owners to format the network settings by their own.

As each type of cloud has its own pros and cons, selection of the cloud model is based on the required business consequence. $\mathrm{CC}$ is attractive, as it free for the infrastructure invest, renting resources along with needs and usage. It permits to decrease operating cost and their load. Moreover, it has a number of benefits in terms of energy efficiency, resource utilization, elasticity, flexibility and performance isolation. 


\section{Cloud of Things (CoT)}

The two technologies IoT and Cloud have got a lot of advancements [11]. It has unique characteristics, as Table 1 depicts. Such dissimilarities has induced the researchers to put forward a novel technology; an integration of cloud and IoT called Cloud of Things (CoT).

Table 1 Different aspects of Cloud and IoT

\begin{tabular}{|l|l|l|}
\hline Various aspects & Cloud & IoT \\
\hline Reachability & Centralized & Universal \\
\hline Displacement & Ubiquitous & Restricted \\
\hline Components & Virtual resources & Real-world \\
\hline Computations & Virtual and unrestricted & Restricted \\
\hline Role of the internet & Delivery service & Point of coverage \\
\hline Storage & Virtual and unrestricted & Restricted \\
\hline Big data & Manages & Storage \\
\hline
\end{tabular}

Typically, IoT can improve their technological constraints (processing, communication, storage) from the virtual unlimited capabilities and resources of cloud, whereas, cloud can extend its scope by dealing with real world things in a more dynamic and distributed routine. Also, it can delivery new services of the everyday life developments. In most of the application cloud acts as intermediate layer in the middle of the applications and the things, for hiding all the complexity and functionalities require to implement it. This will influence the upcoming development, where information gathering, dispensation and transmission may cause new meets [14]. Even though IoT characterized by a very high heterogeneity of devices, protocols and technologies, it lacks in various essential properties, reliability, scalability, efficiency, security, interoperability and flexibility [15], [16]. Cloud simplifies IoT data collection and processing, also empowers quick setup and amalgamation of new things at lower costs for devolvement and data processing [15]. The other advantages of CoT are follows:

Communication: Sharing of data and application are the main aspects of CoT paradigm. Ubiquitous applications can be transfer via IoT, where data collection and distribution by the automation can be done at low-cost. Cloud facilitates an effective solution to establish a connection, tracking and managing any things from anywhere at any time using built-in apps and customized portals [17], [18].

Storage: IoT involves in a large volume of information bases, which in turn generates a plethora of semi or non-structured data called big data [14]. Big data have the following characteristics [16]: data size, type and velocity. Data generated by the IoT is handled by the cloud as it is more flexible and also cost effective [17].

Processing computations: IoT has restricted processing and energy resources, whereas cloud facilitates virtual unlimited processing and on-demand utilities[19].

Scope: As billions of users communicating with each other's and accumulating a variety of information, we can say that the world is rapidly moving in the direction of Internet of Everything (IoE) arena- a network of networks unprecedented opportunities and also new risks. CoT paradigm facilitates to the new smart services and extends the cloud applications via the things [2], [17], also giving introduction to the Things as a Service paradigm [20], [21].

New meets: CoT empowers new developments for smart applications, objects and services[9], [15], [22] Some of the new meets are following:

$\checkmark \quad$ SaaS (Sensing as a Service): It deals with sensor data

$\checkmark \quad$ EaaS (Ethernet as a Service): It provides connectivity to handle remote objects/ devices

$\checkmark$ SAaaS (Sensing and Actuation as a Service): It gives automatic control logics

$\checkmark \quad$ IPMaaS (Identity and Policy Management as a Service): It deals with identity management and policies.

$\checkmark$ DBaaS (Database as a Service): It manages the databases.

$\checkmark \quad$ SEaaS (Sensor Event as a Service): It dispatches the sensor event messages

$\checkmark$ SenaaS (Sensor as a Service): It manages the remote sensors

$\checkmark \quad$ DaaS (Data as a Service): It facilitates the access to any kind of data.

\section{CoT Applications}

The integration of cloud and IoT (CoT) has given a birth to a new set of smart applications and services and it can impact our everyday life as shown in Fig. 4. 


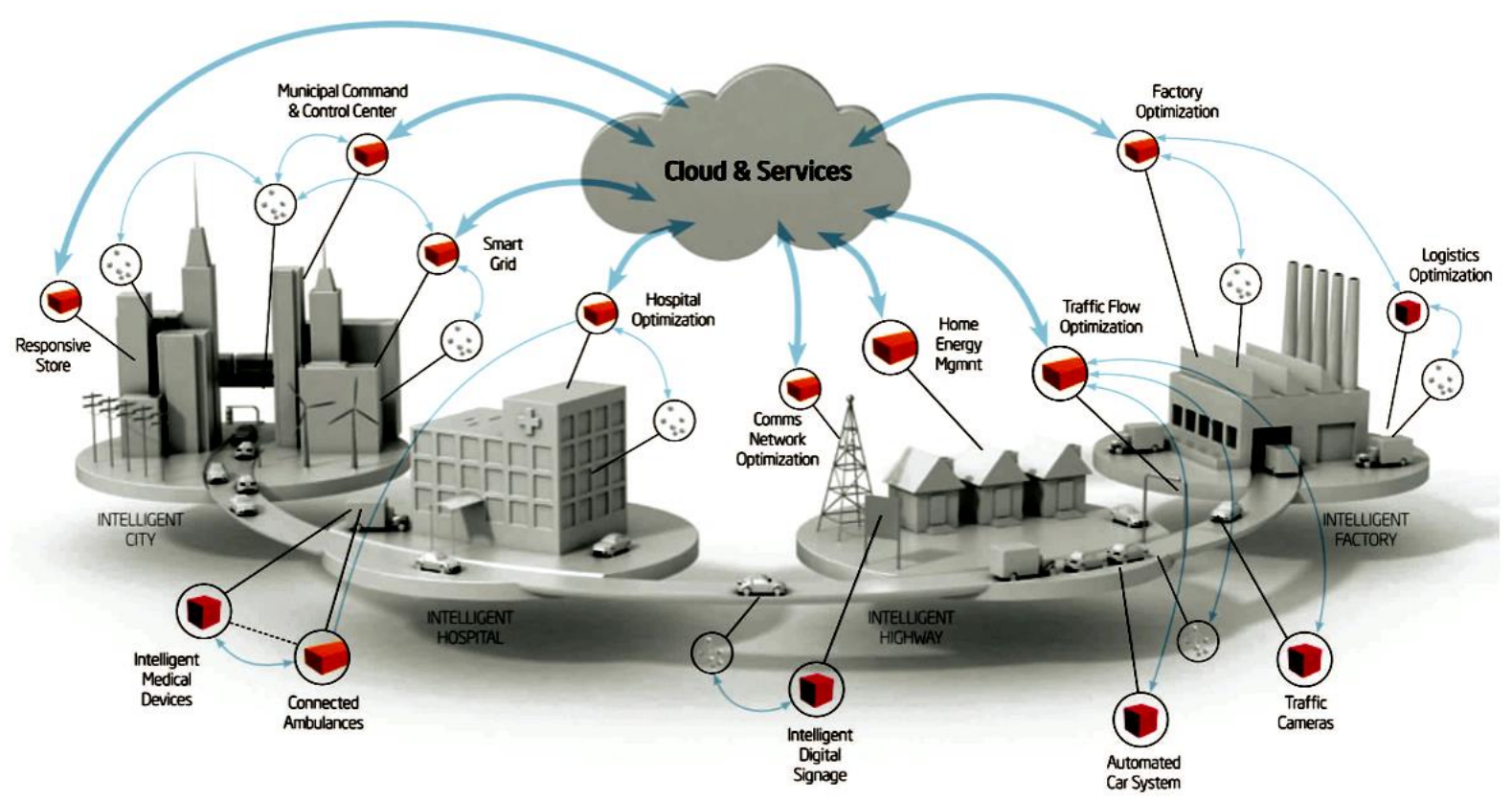

Fig. 4: Applications of CoT [11]

Table 2: Applications of CoT

\begin{tabular}{|c|c|}
\hline Application & Description \\
\hline Smart city & $\begin{array}{l}\text { The generation of smart city services enables the } \\
\text { interaction of surrounding environment and it } \\
\text { creates new opportunities for contextualization } \\
\text { and geo-awareness. }\end{array}$ \\
\hline Healthcare & $\begin{array}{l}\text { It brings many innovative services like collect- } \\
\text { ing patients' data from medical devices of net- } \\
\text { work connected sensors, storing and processing } \\
\text { of those data in cloud as Electronic healthcare } \\
\text { records. (intelligent medicine control and hospi- } \\
\text { tal management, smart wearables for health } \\
\text { monitoring) }\end{array}$ \\
\hline Smart home & $\begin{array}{l}\text { It adopts various embedded devices and cloud } \\
\text { services to bring out the automated home appli- } \\
\text { cations like security control, smart metering. }\end{array}$ \\
\hline Video surveillance & $\begin{array}{l}\text { Complex video analytics need cloud solutions } \\
\text { (VSaaS) for video storage and processing [23]. }\end{array}$ \\
\hline $\begin{array}{l}\text { Automotive and mo- } \\
\text { bility }\end{array}$ & $\begin{array}{l}\text { It brings many benefits like increasing road } \\
\text { safety, managing traffic and parking, reducing } \\
\text { road congestion, vehicle warranty analysis [24]. }\end{array}$ \\
\hline Smart grid and energy & $\begin{array}{l}\text { It enables consumer with smart management of } \\
\text { energy consumption (renewable energy re- } \\
\text { sources) }\end{array}$ \\
\hline Smart logistics & $\begin{array}{l}\text { It makes easy of goods transition from producer } \\
\text { and consumer by enabling tracking the transits } \\
\text { of goods. }\end{array}$ \\
\hline $\begin{array}{l}\text { Environmental moni- } \\
\text { toring }\end{array}$ & $\begin{array}{l}\text { It enables the entity that monitors the wide area } \\
\text { of environment and sensors like pollution source } \\
\text { monitoring, air quality monitoring and water } \\
\text { quality monitoring. }\end{array}$ \\
\hline
\end{tabular}

\section{Challenges}

The previous section discussed the benefits and improvement in applications conquered by the integrated technology CoT. This section discusses the challenges behind the improvement of application scenarios [14]. Those challenges are elaborated below:

\section{Privacy and security:}

When some of IoT applications upgrade with cloud, issues arise because of the discrepancy in the knowledge about physical location of data, trustiness in service provider, and knowledge of service level agreements [25]. Such applications may undergo to the attacks namely SQL injection, session riding, cross site scripting and side-channel and also it may affect by the vulnerabilities such as virtual machine escape and session hijacking. The computing power constraints imposed by the things do not allow employing the public key cryptography also.

\section{Heterogeneity:}

The important and non-negligible challenge is heterogeneity of platforms, devices, operating systems and services. The interaction with huge amount of heterogeneous things has to be properly identified in the cloud among the various levels. This challenge comprises the aspects in terms of interoperable programming interfaces [26], unifying platforms and middleware, and copying with data diversity [25], etc.

\section{Performance:}

The main challenge is obtaining a stable network performance. For instance, if the broadband increases, it is not easy to follow the storage and computation [13], [17]. As timeliness is heavily impacted with unpredictability issues, real-world applications might be affect extensively.

\section{Reliability:}

When CoT is implemented for mission-critical applications, reliability issues usually rises. For example, vehicular networking and communication is unreliable [27].

\section{Big data:}

The integration of cloud and IoT clearly states that IoT will be a one of the source of data (big data) and the cloud can facilitate to store that data for a long period of time [10]. Handling such a large volume of data is an issue, as the performance of application is heavily subject to the properties of data management service. Defining a solution for resolving the data management issues is still a big challenge [19]. Moreover, data integrity is a significant issue, due to service quality, security and privacy challenges [28].

Legal aspects: It is very important in certain research applications. For example, service provider should adopt for international regulations and users should offer certain donation to data collection [29].

Monitoring: It is an essential task in cloud for dealing resources, planning the capacity, performance and security and troubleshoot- 
ing also [30]. CoT take over the monitoring task from cloud, but it may get affect by volume and velocity features of IoT.

Large scale: CoT can design the new applications by analyzing and integrating information spreading out from devices like sensors [31-33]. Some applications internally require the interaction with a large number of devices like distributed area environments. This large scale of systems makes the usual challenges harder to overwhelm.

\section{Conclusion}

This paper presented the applications and challenges of integrated technology, cloud of things (CoT). First, it discussed the basics of IoT and cloud computing along with its pros and cons. Also, it described the thing that strived to integrate technologies. CoT paradigm will be enhanced for every applications and services too. It can promote improved healthcare and smart city applications, business openings, etc. The challenges like scalability and security; the heterogeneity of devices and technologies; legal aspects and privacy preservation behind CoT is also discussed. The future research direction of this integrated technology may include the large support in communication models, security related software like firewalls, intrusion detection, surveillance, identification of managing the naming and addressing the things.

\section{References}

[1] Zhou, J., Leppanen, T., Harjula, E., Ylianttila, M., Ojala, T., Yu, C., Jin, H., and Yang, L. T. (2013) Cloudthings: A common architecture for integrating the internet of things with cloud computing. In Computer Supported Cooperative Work in Design (CSCWD), 2013 IEEE 17th International Conference on, pp 651-657, IEEE.

[2] Chang, K.-D., Chen, C.-Y., Chen, J.-L., and Chao, H.-C. (2011) Internet of things and cloud computing for future internet. In Security-enriched urban computing and smart grid, pp 1-10, Springer.

[3] Atzori, L., Iera, A., and Morabito, G. (2010) The internet of things: A survey, Computer networks, Elsevier 54, 2787-2805.

[4] Bassi, A., and Horn, G. (2008) Internet of Things in 2020: A Roadmap for the Future, European Commission: Information Society and Media 22, 97-114.

[5] Alamri, A., Ansari, W. S., Hassan, M. M., Hossain, M. S., Alelaiwi, A., and Hossain, M. A. (2013) A survey on sensor-cloud: architecture, applications, and approaches, International Journal of Distributed Sensor Networks, SAGE Publications Sage UK: London, England 9 , 917923.

[6] Alhakbani, N., Hassan, M. M., Hossain, M. A., and Alnuem, M. (2014) A framework of adaptive interaction support in Cloud-based Internet of Things (IoT) environment. In International Conference on Internet and Distributed Computing Systems, pp 136-146, Springer.

[7] Akyildiz, I. F., Su, W., Sankarasubramaniam, Y., and Cayirci, E. (2002) Wireless sensor networks: a survey, Computer networks, Elsevier 38, 393-422.

[8] Lee, J. (2013) A view of cloud computing, International Journal of Networked and Distributed Computing, Atlantis Press 1, 2-8.

[9] Atkins, C., Koyanagi, K., Tsuchiya, T., Miyosawa, T., Hirose, H., and Sawano, H. (2013) A cloud service for end-user participation concerning the internet of things. In Signal-Image Technology \& Internet-Based Systems (SITIS), 2013 International Conference on, pp 273-278, IEEE.

[10] Aitken, R., Chandra, V., Myers, J., Sandhu, B., Shifren, L., and Yeric, G. (2014) Device and technology implications of the internet of things. In VLSI Technology (VLSI-Technology): Digest of Technical Papers, 2014 Symposium on, pp 1-4, IEEE.

[11] Botta, A., De Donato, W., Persico, V., and Pescapé, A. (2016) Integration of cloud computing and internet of things: a survey, Future Generation Computer Systems, Elsevier 56, 684-700.

[12] Khan, Z., and Kiani, S. L. (2012) A cloud-based architecture for citizen services in smart cities. In Utility and Cloud Computing (UCC), 2012 IEEE Fifth International Conference on, pp 315-320, IEEE.

[13] CloudPlugs: http://cloudplugs.com/, Accessed: 2018-06-30.

[14] Castro, M., Jara, A. J., and Skarmeta, A. F. (2013) Smart lighting solutions for smart cities. In Advanced information networking and applications workshops (WAINA), 2013 27th international conference on, pp 1374-1379, IEEE.

[15] Cerqueira, E., Lee, E., Weng, J.-T., Lim, J.-H., Joy, J., and Gerla, M. (2014) Recent advances and challenges in human-centric multimedia mobile cloud computing. In Computing, Networking and Communications (ICNC), 2014 International Conference on, pp 242246, IEEE.

[16] Dores, C., Reis, L. P., and Lopes, N. V. (2014) Internet of things and cloud computing. In Information Systems and Technologies (CISTI), 2014 9th Iberian Conference on, pp 1-4, IEEE

[17] Chen, S.-Y., Lai, C.-F., Huang, Y.-M., and Jeng, Y.-L. (2013) Intelligent home-appliance recognition over IoT cloud network. In Wireless Communications and Mobile Computing Conference (IWCMC), 2013 9th International, pp 639-643, IEEE.

[18] Christophe, B., Boussard, M., Lu, M., Pastor, A., and Toubiana, V. (2011) The web of things vision: Things as a service and interaction patterns, Bell labs technical journal, Nokia Bell Labs 16, 55-61.

[19] Copie, A., Fortis, T.-F., and Munteanu, V. I. (2013) Benchmarking cloud databases for the requirements of the internet of things. In Information Technology Interfaces (ITI), Proceedings of the ITI 2013 35th International Conference on, pp 77-82, IEEE.

[20] Dinh, H. T., Lee, C., Niyato, D., and Wang, P. (2013) A survey of mobile cloud computing: architecture, applications, and approaches, Wireless communications and mobile computing, Wiley Online Library 13, 1587-1611.

[21] Distefano, S., Merlino, G., and Puliafito, A. (2012) Enabling the cloud of things. In Innovative Mobile and Internet Services in Ubiquitous Computing (IMIS), 2012 Sixth International Conference on, pp 858-863, IEEE.

[22] Bonomi, F., Milito, R., Zhu, J., and Addepalli, S. (2012) Fog computing and its role in the internet of things. In Proceedings of the first edition of the MCC workshop on Mobile cloud computing, pp 13-16, ACM.

[23] Aguzzi, S., Bradshaw, D., Canning, M., Cansfield, M., Carter, P., Cattaneo, G., Gusmeroli, S., Micheletti, G., Rotondi, D., and Stevens, R. (2013) Definition of a Research and Innovation Policy Leveraging Cloud Computing and IoT Combination, Final Report, European Commission, SMART 37, 2013.

[24] Dobre, C., and Xhafa, F. (2014) Intelligent services for big data science, Future Generation Computer Systems, Elsevier 37, 267-281.

[25] Kumar, L. D., Grace, S. S., Krishnan, A., Manikandan, V., Chinraj, R., and Sumalatha, M. (2012) Data filtering in wireless sensor networks using neural networks for storage in cloud. In Recent Trends in Information Technology (ICRTIT), 2012 International Conference on pp 202-205, IEEE.

[26] Jararweh, Y., Al-Ayyoub, M., Benkhelifa, E., Vouk, M., Rindos, A., and others. (2015) SDIoT: a software defined based internet of things framework, Journal of Ambient Intelligence and Humanized Computing, Springer 6, 453-461.

[27] He, W., Yan, G., and Da Xu, L. (2014) Developing vehicular data cloud services in the IoT environment, IEEE Transactions on Industrial Informatics, IEEE 10, 1587-1595.

[28] Luckow, A., and Kennedy, K. (2017) Data Infrastructure for Intelligent Transportation Systems. In Data Analytics for Intelligent Transportation Systems, pp 113-129, Elsevier.

[29] Agarwal, N., Chauhan, S., Kar, A. K., and Goyal, S. (2017) Role of human behaviour attributes in mobile crowd sensing: A systematic literature review, Digital Policy, Regulation and Governance, Emerald Publishing Limited 19, 168-185.

[30] Saqib, M. (2017) Cloud Monitoring: A Survey, Cloud Computing and its Applications 8, 8

[31] Lazarescu, M. T. (2013) Design of a WSN platform for long-term environmental monitoring for IoT applications, IEEE Journal on emerging and selected topics in circuits and systems, IEEE 3, 45-54.

[32] Petrolo, R., Loscri, V., and Mitton, N. (2014) Towards a smart city based on cloud of things. In Proceedings of the 2014 ACM international workshop on Wireless and mobile technologies for smart cities, pp 6166, ACM.

[33] Rao, B. P., Saluia, P., Sharma, N., Mittal, A., and Sharma, S. V. (2012) Cloud computing for Internet of Things sensing based applications. In Sensing Technology (ICST), 2012 Sixth International Conference on, pp 374-380, IEEE. 